\title{
Coaching challenging executives
}

Book or Report Section

Accepted Version

Kets de Vries, M. and Rook, C. (2018) Coaching challenging executives. In: Passmore, J., Underhill, B. and Goldsmith, M. (eds.) Mastering Executive Coaching. Routledge. ISBN 9780815372912 Available at https://centaur.reading.ac.uk/72928/

It is advisable to refer to the publisher's version if you intend to cite from the work. See Guidance on citing.

Publisher: Routledge

All outputs in CentAUR are protected by Intellectual Property Rights law, including copyright law. Copyright and IPR is retained by the creators or other copyright holders. Terms and conditions for use of this material are defined in the End User Agreement.

\section{www.reading.ac.uk/centaur}

\section{CentAUR}

Central Archive at the University of Reading

Reading's research outputs online 


\title{
Coaching Challenging Executives*
}

\author{
Manfred F. R. Kets de Vries \& Caroline Rook
}

\section{Introduction}

Finding the rational homo economicus as described in management textbooks seems to be nothing more than an exercise in futility. Most executives are not paragons of rationality. It is even a truism saying that these people don't exist. Dysfunctional behavior characterizes the actions of too many executives. And when there is rot at the top, the repercussions can be consequential. When a leader's psychological makeup is problematic, it can have a serious contagious effect. If that is the case, the organization itself is in danger of becoming a mirror image of the leader's troublesome behavior patterns. ${ }^{1}$ Furthermore, the resulting toxic organizational culture can make the people who work in these organizations sick. ${ }^{2}$ But leadership coaches who have a deep understanding of personality functioning, and are familiar with the appropriate intervention techniques of dealing with these people, can help in addressing these mental health issues in order to bring about more effective leadership practices, and ultimately more healthy organizations. ${ }^{3}$

In this chapter, we look at the mental health of leaders, its impact on the organization, and the role of coaching executives in the workplace. Specifically, we explore four regularly encountered toxic behavior patterns amongst leaders that can derail their organizations. For each personality type, we describe the conditions underlying the behavior pattern, how to recognize the pattern, how to coach individuals who exhibit this pattern, as well as to provide a real live case study to illustrate how coaching can bring about better ways of running their organizations.

\footnotetext{
* A chapter to be published in Mastering Executive Coaching (2018), Jonathan Passmore and Bryan Underhill, (eds.). Abingdon: Routledge.
} 


\section{Mental health and coaching in the workplace}

At work, at least one in four people experience mental health issues such as depression or anxiety ${ }^{4}$. Although a range of factors may contribute to psychological problems, senior executives in particular are at risk, due to the demands and pressures of the job. For example, factors such as the loneliness at the top, transferential issues regarding authority, and a lack of constructive feedback from peers and team members, can turn what were previously very effective ways of working into very unhealthy behavioral patterns ${ }^{5}$. To illustrate, although a top executive such as Jack Welch, the former CEO of General Electric, can be viewed as quite narcissistic, his specific leadership style helped him to act as a very creative, gifted strategist, willing to take great risks in order to push for positive changes in his organization. We can add, however, that it would not have taken much to transform him into a destructive narcissist, if the people he worked with had blindly listened to him, and had been fearful of providing him with feedback needed to keep him solidly grounded in reality. ${ }^{6}$ For people like Jack Welch, leadership coaching was helpful as a check on potentially dysfunctional behavior.

Generally speaking, leadership coaching can be a force for the good in helping executives become aware of toxic behavior patterns. Coaches can encourage executives to make efforts to change, and while doing so, to help an organization flourish. ${ }^{7}$ Furthermore, coaches can make executives aware of how they may resort to primitive defense mechanisms such as splitting, denial, and projection that can prevent them from making sound decisions. They can also point out irrational fears, self-defeating behavior patterns, and outdated self-perceptions that could hold them back from healthy functioning, and from creating sustainable, high-performance organizations.

\section{The psychodynamic approach}

Although different approaches to coaching should be used according to the problems encountered, the psychodynamic approach aims to develop a deeper understanding of what lies beneath the surface of human and organizational functioning. ${ }^{8}$ Why this approach can be so effective is that sustainable change cannot be achieved without an understanding of the invisible barriers and root-causes that can block change. ${ }^{10}$ If the underlying factors aren't dealt with, any attempt at change will turn into a Band-Aid 
ritual, providing only temporary relief. The psychodynamic orientation enables the client to dive deep into deciphering what is really going on in terms of the motivational forces limiting the achievement of goals, team alignment, and high performance. Through exploring both their past and present histories, clients may realize that many of their feelings, memories and fantasies are blocked from their immediate awareness but nevertheless influence their thinking and behavior. In creating greater awareness of these various thought processes, the expectation is that executives would no longer remain its prisoners. The insights provided through these interventions would enable them to have a greater freedom of choice ${ }^{11}$ and the conditions for mind-set change that's needed for sustainable improvement. ${ }^{12}$

The goal of executive coaches is to expand their client's ability for emotional regulation. Through coaching, they can fine tune their reflective capabilities to preempt primitive defenses - to prevent "acting out." As a caveat what should be added is, that in the case of severe personality pathologies, we have to be careful in navigating the boundaries between coaching and psychotherapy. More traditional coaching interventions may turn out to be ineffective, and even damaging, when the client suffers from a severe case of psychopathology ${ }^{13}$.

\section{The role of the executive coach in confronting mental health issues}

A major mandate of executive coaches is to help executives become more reflective practitioners ${ }^{14}$. While working with their clients, they can act as a mirror to reflect their clients' ambitions, strengths, weaknesses, and avenues for positive personal development. By creating a safe transitional space, and by using their own unconscious as a receptive organ, ${ }^{15}$ otherwise "undiscussables" 16 topics can be brought to the surface and dealt with. While doing so, executives may discover that mental and behavioral patterns that may have been effective at one stage in their life have now become counterproductive ${ }^{17}$.

In the next section, we will explore in detail four types of challenging personalities: narcissistic, bipolar, psychopathic and obsessive-compulsive. 


\section{The Narcissistic Leader}

A healthy dose of narcissism is needed for effective leadership functioning. Without it, there will not be a foundation for self-confidence, self-expression and assertiveness. ${ }^{18}$ When the narcissistic strivings of a leader become too overpowering, however, their actions can become toxic. What signifies this kind of behavior are leaders' grandiose fantasies about themselves, the exhibition of very selfish behaviors, and having a great sense of entitlement, all qualities that may compel them to pursue their personal interests at any cost.

\section{How to recognize the condition}

When referring to narcissism, we should also keep in mind that we are all narcissistic to some degree. It is an excess of narcissism, however, that can make this condition pathological. The foundation of narcissistic pathology is typically set in childhood through defective kinds of parenting (either over-, under-, or inconsistent stimulation), which contributes to the developing child's unstable sense of self. Over time, the child may turn into an insecure adult, who is constantly in search for external validation ${ }^{19}$

Narcissists know how to exploit others to reach their goals. Due to their high sense of entitlement, they think that rules are made not made for them. As such they do not feel beholden to the rules and moral boundaries that guide other people. And when they do not get what they think they deserve, they are prone to outbursts of anger. These people constantly need to seek the limelight, desperate as they are in searching for admiration, which blinds them to the need of others.

\section{Coaching narcissistic executives}

When coaching the narcissistic executive, the coach should avoid anything that might upset the executive's fragile sense of self. Any strong form of disagreement is quickly perceived as a personal attack. Therefore, before presenting the client with his or her dysfunctional behavior, a foundation of trust has to be established as a basis for a safe working alliance. What this implies is that when starting a coaching relationship the coach should acknowledge the need of their client to be recognized and show empathy to gain his or her trust. This ground-laying work will enable the coach, at a later stage, to help narcissists really deal with their dysfunctional behavior. 
The coach should be aware of the fact that narcissists also tend to have a rather binary mindset, meaning that they idealize or devaluate the other. In particular, people in positions of authority are quickly idealized - although (the coach should also keep in mind) devaluation is always around the corner. Not much is needed to have narcissists change their minds. Experienced coaches, however, can use the narcissist' tendency for idealization to gain their initial trust so as to be able to confront some of their dysfunctional behavior patterns at a later stage. Also, given the competitive nature of narcissists, their inner drive to be successful can be leveraged to motivate them to make changes in their behavior.

Apart from one-on-one coaching, the leadership coach could also engage in team coaching ${ }^{20}$ as another way to help address these executives' destructive narcissistic behavior patterns. In a group setting, the dysfunctional ways of acting out of the narcissistic executive would become more noticeable. This being the case, group coaching offers the opportunity of the others (not just the coach) to make suggestions for change. In such a setting, the narcissistic executive will find it more difficult to ignore the feedback. The group effect enables the other executives to challenge the narcissist's dysfunctional ways of working with others. Under the influence of peer pressure, the narcissistic executive will more likely make efforts to adapt to more acceptable behavior patterns. Of course, before such a team coaching process can occur and be effective, there should be a minimum amount of trust among the members of the team. Without this trust, it will be difficult to bring about the changes that are needed. The challenge for team members is to give narcissists critical and constructive feedback that can be tolerated in light of this person's fragile self-esteem. Similarly, the leadership coach, in his or her facilitating role, needs to be able to sense what the narcissist can tolerate and be astute to know when "to strike when the iron is cold," meaning to be very careful in judging how far he or she can go.

\section{A case study}

Simon entered a coaching engagement to prepare himself for possible succession into the CEO role in his organization. Although he was seen as the most promising candidate within the company, some of the non-executive directors remained doubtful. For example, Simon had embarked on extensive expansion plans despite cautionary feedback from his colleagues. Also, his proposal to buy a corporate private 
jet, despite the precarious financial situation of the organization, was also seen as a troublesome sign. Simon also seemed to be keen to regularly appear in the press, and to bypass the guidelines from the corporate communications department. It was clear that he very much liked the limelight. What added to the various concerns was that some of his colleagues felt somewhat exploited when working with Simon. According to them, he was very good in using others, making him not much of a team player.

Given his tendency to slot people into the positions of either heroes or villains, Simon quickly viewed his coach as an authority figure. His willingness to do so allowed the coach space and legitimacy to bring up more delicate, constructive suggestions. Instead of explicitly targeting problematic and pathological behaviors, the coach framed most of the discussions around the attainment of the ultimate external prize: how to turn the succession to the CEO position into a reality. For example, in his dealings with Simon, the coach did not directly criticize Simon's self-serving demands, but instead reframed the situation, which helped Simon reflect on his actions. The coach commented that although a private jet was very practical for a busy executive like him (hence empathizing with him), however, at this point in time, this idea might not be the wisest thing to do in the context of the cost-cutting efforts that were occurring throughout the entire organization (providing context and alternative ways of framing the situation). In addition, the coach used Simon's competitive streak to instigate behavioral change. He mentioned that as Simon was in a "race" with a number of outside candidates for the CEO position, it would more strategic and advantageous to toe the line and adapt to some of the wishes of the nonexecutive directors. As time passed, the coach, while being very supportive of Simon's ambitions, was able to help him change some of his more dysfunctional qualities.

\section{The Bipolar Leader}

Executives with mild forms of bipolar disorders oscillate between having the feeling that anything is possible, to suddenly feeling that everything is hopeless. Whereas challenging or traumatic events in a person's life can lead to depression, the bipolar condition is more of a genetic issue - mostly caused by physical changes in the brain. In more severe cases, this condition needs to be treated with medication (lithium), in 
combination with psychotherapy. ${ }^{21}$

What's most challenging with people who suffer from this disorder are their mood swings, thus the popular name of manic-depressive disorder. These mood swings can have a very negative effect on their working and family lives. Given their behavior, people who are bipolar, often suffer from a high degree of career derailment, may become estranged from family and friends (due to their disturbing behavior), have problems with promiscuity, may get themselves into financial difficulties, and may be prone to alcohol and drug abuse.

\section{How to recognize the condition}

Bipolar executives oscillate between manic and depressive states. In their manic state, they will be full of energy, can be euphoric, and be extremely optimistic about whatever challenges they are up against. Consequently, their outlook translates into the kinds of leadership behavior patterns that can be greatly inspiring. Their energy galvanizes the others to positively transform projects and organizations. When they are in a depressive state, however, bipolar executives experience a sense of fatigue, are overly pessimistic, and tend to withdraw as they feel a sense of inner deadness.

\section{How to coach bipolar executives}

Comparable in establishing a coaching relationship with a narcissist, for executives with bipolar tendencies, the coach needs to help create awareness among these people of the ramifications of their personality makeup. Bipolars need to realize how their behavior affect their relationships with others; that although their behavior can be extremely energizing, their mood-swings can also be very destructive. Furthermore, their overly optimistic outlook (when they are on the upswing) can be very visionary, but can also be unrealistic, and could set the organization, in the long-term, up to fail.

In dealing with these people, coaches should realize that the reality testing abilities of bipolar people are quite limited. In their eyes, the world seems either full of exciting opportunities or is completely hopeless. What's more, to help moderate their mental state, they are not eager to accept the obvious recommendation: to take medication. On the contrary, taking medication can make their life feel flat as it will contain their feelings of euphoria. But although they may be reluctant to take medication, they may 
be incentivized to change when the consequences of doing nothing are made explicit to them. The coach can also explore with them how, by restructuring their working life, they may acquire a greater sense of well-being. Of course, when dealing with a severe bipolar disorder, psychotherapy combined with medication is needed to stabilize the mental state of the executive.

\section{A case study}

Peter was motivated to seek coaching due to a feeling that he was falling apart which he explained was caused by the pressures that came with his job. Until recently, in his efforts to be a successful entrepreneur, he had been very excited to create new business opportunities for his organization. Now, however, all his responsibilities were becoming too much. As things were, presently, he felt extremely frustrated, overwhelmed by the endless stream of emails and phone messages, and the constant demands of the people in the business. Furthermore, what also troubled him, was a persistent and ominous fear that his business might go bankrupt.

The coach realized that Peter, without being fully aware of it, subjected himself to a thought pattern called catastrophizing. Given the way his mind was functioning, he expected a disaster to happen at any moment. He also mentioned his bouts of depression, having gone through a very severe one recently. He explained it as a result of his failure to successfully acquire another company. What's more, he took this defeat as a sign that new failures were just around the corner. His fatalistic outlook created in him an enormous amount of stress, and great sense of helplessness.

To obtain more insight into the psychology of Peter, the executive coach asked him if he could talk to some of the people he was in close contact with. After gaining his permission, the coach talked to a number of different executives in the organization to get a better idea how others perceived Peter. It became quickly apparent that Peter had tendencies to micromanage as a way to create "the illusion of control" to prevent major disasters from happening. At the same time, it was exactly this tendency to micro-manage and to take all the responsibilities onto his shoulders that accentuated his level of stress.

As a first step, the leadership coach helped Peter to restructure his job by delegating more tasks and decisions. To find a better way of working gave a great sense of relief, 
and improved his sense of well-being. Also, the coach helped him reframe some of his distorted outlooks on life, creating a greater awareness of his tendency towards cognitive distortions. In addition, the coach pushed Peter to visit a pharmacologicallyoriented psychiatrist to get the kinds of medication that could help him balance his mood states.

\section{The Psychopathic Leader}

One might also call psychopaths in organizations "seductive operational bullies" (SOBs). ${ }^{22}$ Often, their charismatic and Machiavellian qualities help them reach senior executive positions. Given their talents at "mimicry," they know how to please the people that count in the organization. Quite eager "to win" at any cost, many of them have the dedication and business acumen that would create the appearance of success. Most often, however, their success comes at the exploitation and abuse of others. These people are infamous for taking credit for other people's work.

In organizations, psychopathic executives are very talented in making the people they work with emotionally dependent on them; they prey on the emotional vulnerabilities of others. Also, they excel at power plays. Given their seductiveness - their ability to use smoke and mirrors to create the appearance of success - they are often perceived as the ideal employee. If top management does not spot their destructive disposition early on, however, such executives may be slotted for a fast track career to the top, where it will be more difficult to contain their destructive tendencies.

\section{How to recognize the condition}

We should keep in mind that when we talk about psychopaths in organizations, we refer to less extreme forms of psychopathy-in other words, psychopaths "light". Usually, when the word psychopath is used, we are referring to a more serious condition in which people are often genetically born with a lack the capacity to form any emotional bonds or do not possess any sense of social responsibility- the people that may end up in prisons. In organizations, SOBs exhibit psychopathic behaviors but are still able to function and even succeed in their environment.

SOB leaders are able thrive because it is so difficult to nail down their dysfunction, 
due to their exceptional skills at manipulation and impression management. Given their Machiavellian disposition, they are quick to rationalize and convince others of their unethical behavior. Emotionally deficient and lacking a moral conscience, psychopathic executives are unaware of the effect they have on others. ${ }^{23}$ They are blind to their own shortcomings, obsessed as they are by the game of winning.

Probably, in their early development, executives with milder forms of psychopathy were not necessarily born without having a total incapacity to experience emotions. What exactly contributes to their psychopathic disposition, however, is a nature/nurture puzzle that remains unsolved. In some instances, we can hypothesize that a deactivation of emotional bonding may have developed during childhood through repeated disillusionment, and physical, sexual abuse or other forms of mistreatment.

\section{Coaching SOB executives}

It is extremely difficult, if not impossible, to successfully coach an executive with psychopathic tendencies, as their emotional capacity is impaired or deactivated. Furthermore, what makes coaching psychopaths such an uphill challenge is the fact that they are exceptionally skilled in manipulating any relationship-including the one with the leadership coach. Psychopathic executives will go through great efforts "to seduce" the coach, trying to make him or her an ally against other people in the organization - the ones who may have forced coaching onto him or her. Alternatively, the psychopathic executive will try to impress the coach to gain other advantages. ${ }^{24}$ One way, however, to engage in a grounded and meaningful discussion with this kind of executive is to use a 360-degree feedback process to gather perspectives of others, which collectively form a basis for discussion. It could lead to a realistic discussion of the motivation and source of the SOB's people management style.

\section{A case study}

Arnold was seen as one of the high potentials in an organization. At the same time, the comment was made that he seemed to "rub too many people the wrong way." In order to ensure that he would be a candidate for a fast track position, coaching had been suggested to help improve his leadership skills. Arnold happily accepted the coaching offer as he saw it as an indication that he would soon be promoted. 
Subsequently, the coach conducted a 360-degree feedback leadership survey to help obtain information on how Arnold was perceived by others - and what steps could be taken to improve his leadership skills. Surprisingly to the coach, hardly any of Arnold's colleagues had given him feedback. When a reminder was sent to them to do so, the feedback he received was very negative. From the information given, it was clear that Arnold never owned up to his mistakes. He would shift responsibilities onto others, had no respect for confidentiality, and would quickly take credit for other people's work.

To not alienate Arnold, the coach did not directly confront him about this consistent negative feedback but asked him what he found surprising in the feedback he received; what feedback he saw as fair and what he saw as unfair; and how he might adapt some of his leadership behavior to more productively work with others.

During the coaching process, Arnold tried to convince the coach about the progress he was making. But the coach was quite uncertain if this progress was real. Was what was described as progress merely an exercise in smoke and mirrors? Eventually, despite the reservations of the coach, Arnold did manage to convince his bosses to stop the coaching engagement - that he had changed for the better. Subsequently, he was promoted into a senior position. But not surprisingly to the coach, not long after, Arnold was fired, rumors going around that he was caught in unethical behavior like accepting bribes to steer contracts to specific suppliers.

\section{The Obsessive-Compulsive Leader}

Many executives display elements of obsessive-compulsive behavior as control and order is part of what organizational life is all about. But in some instances, such behavior can go too far. When being perfect becomes the only acceptable standard, it can cause serious problems. Ironically, in their obsession with perfection, executives with this leadership style stifle creativity and impair the workflow of the organization.

Moreover, what makes these people difficult to work with is that obsessivecompulsive individuals often come across as stubborn, unreceptive to considering alternatives, and suspicious of others. They find it hard to build close relationships 
with colleagues and team members, making them not a natural for effective teamwork.

\section{How to recognize the condition}

In many instances, the perfectionism of obsessive-compulsive executives can interfere with their task completion. Often, they act indecisively; the word procrastination is not strange to them. For many of them, also the term analysis-paralysis is very appropriate, as they cannot tolerate making mistakes. But as the expression goes: people, who don't make any mistakes, don't do anything. Mistakes are part and parcel of organizational life. No wonder that for these people, decision-making can become such a drawn-out, difficult process. Also, obsessive-compulsives are not very good in establishing emotional bonds. They express affection in a too controlled manner. They can become quite uncomfortable when dealing with highly emotionally, expressive people. And as is the case of many other personality disorders, the origins of this behavior can be found in childhood. Most likely, the foundation of obsessivecompulsive behavior is created by being exposed to emotionally withholding, overprotective, or over-controlling caretakers.

\section{Coaching obsessive-compulsive leaders}

Through the process of coaching, obsessive-compulsive executives may realize the negative effects and source of their controlling behavior. Also, they may become more aware of the kinds of secondary symptoms that accompany this condition (such as anxiety and depression).

Often, obsessive-compulsive executives don't realize the negative effect that their perfectionism has on others. They are also not aware that their seemingly cold emotional behavior alienates the people they work with. Thus, given their mental outlook, the coach could explore with these executives what "good enough" rather than "perfect" would look like. It's essential to allow these executives to accept different ways of working, and other ways of achieving success. Also, experimenting with more effective ways of dealing with people will be an important factor in improving their leadership skills.

\section{A case study}


Rita was recently appointed as CEO of a large organization after a serious search to fill the position. Although she appeared to be the best candidate for the job, the chairman of the board had a number of reservations. He was concerned that her rigid way of working and her obsession with details would make it hard for others to helping be successful in the position. He thought that an onboarding coaching arrangement would be helpful. Rita saw the offered coaching engagement as a good opportunity, in light of her anxiety of being able to deliver.

During the coaching process, the coach explored with Rita the up- and downsides of her rather perfectionistic tendencies. After a number of sessions, she acknowledged her difficulties in prioritizing, and in making decisions. She recognized that she should stop tinkering with strategic proposals for board meetings. She should be satisfied in creating a "good enough" report rather than a "perfect" one. She had not been aware before that asking her team members to endlessly change strategic documents and project plans frustrated them immensely. Furthermore, from talking to other executives, the coach learned that Rita's workaholism created serious work-lifebalance issues among the people that worked for her. Upon prompting, she admitted that things at home were not great, particularly as her husband and children found her not only increasingly absent but also emotionally distant.

Gradually, throughout the coaching process, Rita learned to control herself when things did not go hundred percent her way. She also became better at delegation. This change in behavior gave her more space. It helped her to adopt a more reflective approach to her leadership style which resulted in much more positive relationships with her team and the board members. Furthermore, it also made for more time for her family.

\section{Conclusion}

Executives often fail to recognize their irrational side. They may be oblivious of the negative effects that they have on others. In making this observation, it should be reiterated that irrationality is part of the human condition. All of us have moments of irrationality. Some executives may even be highly successful despite or maybe because of their mental health challenges, as their symptoms may be adaptive and reinforced by the specific organizational cultures they work in. However, in the long- 
term, these executives could also make themselves and others around them sick due to their toxic work behavior. In such cases, as this chapter has shown, leadership coaches can be of great help to spot the danger signs and support the executive in exploring more productive rather than destructive ways of leading. In this chapter, to illustrate this point, we have examined a number of common personality disorders that can be found among executives. We have also outlined a number of intervention techniques available to coaches to tackle these issues in order to create more effective leadership and ultimately healthier organizations.

Thomas Jefferson once said that "Nothing can stop the man with the right mental attitude from achieving his goal; nothing on earth can help the man with the wrong mental attitude." Leadership coaches can do much to make the first observation become a reality. 


\section{Recommended reading}

Kets de Vries, M. F. R. (2016). You will meet a tall, dark stranger. Executive coaching challenges. Basingstoke: Palgrave Macmillan.

Millon, T., Grossman, S., Millon, C., Meagher, S., \& Ramnath, R. (2004). Personality disorders in modern life (2nd ed.). New York: John Wiley \& Sons.

\section{Web resources}

Kets de Vries, M. F. R. (2014). Coaching the toxic leader. HBR Blog. Retrieved from: https://hbr.org/2014/04/coaching-the-toxic-leader

Berglas, S. (2002). The very real dangers of executive coaching. HBR Blog. Retrieved from: https://hbr.org/2002/06/the-very-real-dangers-of-executive-coaching

Mental Health Foundation (2017). Managing mental health in the workplace. [Ebook] Retrieved from: https://www.mentalhealth.org.uk/publications/managingmental-health-workplace

\section{References}

${ }^{1}$ Kets de Vries, M. F. R. and Miller, D. (1984). The neurotic organization: Diagnosing and changing counterproductive styles of management. San Francisco: Jossey-Bass.

${ }^{2}$ Kets de Vries, M. F. R. (2016). You will meet a tall, dark stranger: Executive coaching challenges. Basingstoke: Palgrave Macmillan.

${ }^{3}$ Kets de Vries, M. F. R. (2014). Coaching the toxic leader. Four pathologies that can hobble an executive and bring misery to the workplace - and what to do about them. Harvard Business Review, 92(4), 100-109. 
${ }^{4}$ Mental Health Foundation (2017). Managing mental health in the workplace. [Ebook] Retrieved from: https://www.mentalhealth.org.uk/publications/managingmental-health-workplace

${ }^{5}$ Kets de Vries, M. F. R., Korotov, K., Florent-Treacy, E., \& Rook, C. (2015). Introduction: A psychodynamic approach to leadership development. In: M. F. R.Kets de Vries, K. Korotov, E. Florent-Treacy, \& C. Rook (Eds.), Coach and couch. The psychology of making better leaders (2nd ed.). Basingstoke: Palgrave Macmillan.

${ }^{6}$ Maccoby, M. (2004). Narcissistic leaders: The incredible pros, the inevitable cons. HBR Blog. Retrieved from https://hbr.org/2004/01/narcissistic-leaders-the-incrediblepros-the-inevitable-cons?cm_sp=Article-_-Links-_Top $\% 20$ of $\% 20$ Page $\% 20$ Recirculation

${ }^{7}$ Kets de Vries, M. F. R. (2007). Leadership coaching and organizational transformation: Effectiveness in a world of paradoxes. INSEAD Working Paper, 2008/71/EFE.

${ }^{8}$ de Haan, E., Culpin, V., \& Curd, J. (2011). Executive coaching in practice: What determines helpfulness for clients of coaching? Personnel Review, 40, 24-44.

${ }^{9}$ Kets de Vries, M. F. R., Korotov, K., Florent-Treacy, E., \& Rook, C. (2015). Introduction: A psychodynamic approach to leadership development. In: M. F. R. 
Kets de Vries, K. Korotov, E. Florent-Treacy, \& C. Rook (Eds.), Coach and couch. The psychology of making better leaders (2nd ed.). Basingstoke: Palgrave Macmillan.

${ }^{10}$ Kets de Vries, M. F. R. (2006). The leader on the couch: A clinical approach to changing people and organizations. Chichester: John Wiley \& Sons.

${ }^{11}$ Lee, G. (2010). The psychodynamic approach to coaching. In: E. Cox, T. Bachkirova, \& D. Clutterbuck, The complete handbook of coaching, pp. 23-36. London: Sage.

${ }^{12}$ Sandler, C. (2011). Executive coaching: A psychodynamic approach. Maidenhead: Open University Press.

${ }^{13}$ Berglas, S. (2002). The very real dangers of executive coaching. Retrieved from: https://hbr.org/2002/06/the-very-real-dangers-of-executive-coaching

14 Kets de Vries, M. F. R. (2007). Leadership coaching and organizational transformation: Effectiveness in a world of paradoxes. INSEAD Working Paper, 2008/71/EFE.

15 ibid.

16 Winnicott, D. W. (1951). Transitional Objects and Transitional Phenomena. Collected Papers: Through Paediatrics to Psychoanalysis. London: Tavistock Publications. 
${ }^{17}$ Kohut, H. (1971). The Analysis of the Self. New York: International Universities Press.

${ }^{18}$ Kets de Vries, M. F. R. (2016). You will meet a tall, dark stranger. Executive coaching challenges. Basingstoke: Palgrave Macmillan.

19 ibid.

${ }^{20}$ Kets de Vries, M. F. R. (2017). How to Manage a Narcissist. HBR Blog. Retrieved from https://hbr.org/2017/05/how-to-manage-a-narcissist

${ }^{21}$ Kets de Vries, M. F. R. (2014). Coaching the toxic leader. HBR Blog. Retrieved from: https://hbr.org/2014/04/coaching-the-toxic-leader

${ }^{22}$ Kets de Vries, M. F. R. (2014). The Psycho-path to Disaster: Coping with SOB Executives. Organizational Dynamics, 43, 1, 17-26.

${ }^{23}$ Kets de Vries, M. F. R. (2016). You will meet a tall, dark stranger. Executive coaching challenges. Basingstoke: Palgrave Macmillan.

${ }^{24}$ Kets de Vries, M. F. R. (2014). Coaching the toxic leader. HBR Blog. Retrieved from: https://hbr.org/2014/04/coaching-the-toxic-leader 